Dorota Kolanowska, Piotr Łach, Marta Frąc, Agnieszka Nadolna, Tomasz Fabiszak, Iwona Świątkiewicz, Adam Sukiennik, Sławomir Sielski, Marek Woźnicki, Jacek Kubica

\title{
Percutaneous left atrial appendage closure for thromboembolic prophylaxis in patients with atrial fibrillation. The impact of operator's experience on the procedure course
}

\author{
Corresponding author: \\ Jacek Kubica, MD, PhD \\ Department of Cardiology \\ and Internal Medicine, \\ Nicolaus Copernicus University, \\ Collegium Medicum \\ 9 Skłodowskiej-Curie Street, \\ 85-094 Bydgoszcz, Poland \\ Phone: +48525854023 \\ E-mail: jkubica@cm.umk.pl
}

Folia Medica Copernicana 2015; Volume 3, Number 4, 160-164 10.5603/FMC.2015.0011 Copyright (C) 2015 Via Medica ISSN 2300-5432

\begin{abstract}
Background. Left atrial appendage (LAA) closure represents an alternative strategy to oral anticoagulants in thromboembolic prophylaxis in patients with atrial fibrillation (AF). The LAA closure with the WATCHMAN ${ }^{\text {TM }}$ device has been proved to be non-inferior to warfarin therapy. Nevertheless, this strategy is associated with numerous periprocedural complications. This study was conducted to determine whether the experience of the operating team affects the duration of the procedure and its complication rate.

Methods. This retrospective single-centre study examined LAA percutaneous closure procedures in 43 consecutive AF patients with contraindications to oral anticoagulation ( 13 female, 30 male; mean age $70.98 \pm 10.69$ years). All device implantations were performed by two operators using the WATCHMAN ${ }^{\mathrm{TM}}$ device and the result was assessed by two echocardiographers. We compared the first 22 (group A) with the subsequent 21 procedures (group B).

Results. For group B, a decrease in the overall procedure time (PT) by $28 \%$ (from $83.41 \mathrm{~min} \pm 36.49$ to $59.76 \min \pm 21.70 ; p=0.006$ ) was found, with a subsequent reduction in fluoroscopy time (FT) by $33 \%$ (from $16.59 \mathrm{~min} \pm 7.25$ to $11.2 \mathrm{~min} \pm 7.21 ; \mathrm{p}=0.019$ ) and the volume of contrast medium (CV) by $40 \%$ (from $129.14 \mathrm{~mL} \pm 79.81$ to $78.05 \mathrm{~mL} \pm 33.82 ; \mathrm{p}=0.004$ ). The incidence of periprocedural adverse events and complications was 55\% (12 patients) in group A and 33\% (7 patients) in group B.

Conclusions. The increasing operators' and echocardiographers' experience in LAA closure is associated with reduction in procedure time, fluoroscopy time and contrast volume.

Key words: left atrial appendage closure, WATCHMAN ${ }^{\text {TM }}$ device, complications
\end{abstract}

Folia Medica Copernicana 2015; 3 (4): 160-164

\section{Introduction}

Atrial fibrillation (AF) is the most common sustained arrhythmia [1]. It applies to $2 \%$ of general population of Europe and North America and its incidence increases with age, from about $4 \%$ in those aged $60-70$ years to more than $15 \%$ in those aged 80 years or older [2]. AF may lead to thrombus formation and possible thromboembolic complications. The estimated risk of ischemic stroke in patients with $\mathrm{AF}$ is $5 \%$ per year and is 5 -fold higher than in the general population [3]. Approximately
$90 \%$ of atrial thrombi in non-rheumatic $\mathrm{AF}$ are formed within the left atrial appendage (LAA) [4].

There are several pharmacological antithrombotic options such as warfarin and the novel oral anticoagulants (NOACs). However, at least $20 \%$ of patients have contraindications to warfarin therapy [5]. NOACs, with their efficacy comparable to warfarin, have potentially a better safety profile. Nevertheless, the nature of anticoagulation carries an inseparable risk of bleeding [6]. LAA occlusion represents an alternative strategy for thromboembolic prophylaxis in patients with contra- 
indications to OACs. The PROTECT-AF randomized clinical trial demonstrated that LAA closure with the WATCHMAN device (Boston Scientific, Natick, Massachusetts) is non-inferior to warfarin therapy, and the recent follow-up publication showed the superiority of LAA occlusion $[7,8]$. However, the LAA closure sustained an increased number of procedure-related safety events [8]. A recent indirect comparison of the data from the PROTECT-AF and RE-LY trial revealed that the WATCHMAN device would fail to meet non-inferiority when compared with one of the NOACs - dabigatran [9]. However, a prospective, randomized, head-to-head trial is required to ultimately clarify this issue [9].

The LAA closure has become a reasonable and increasingly accessible option for patients with AF, particularly for those at high risk of bleeding. Moreover, the majority of costs related to this procedure are borne in the first year, while costs for pharmaceutical strategies continue to accrue year-on-year. Thus, LAA closure represents an opportunity for long-term savings to healthcare systems [10]. Nevertheless, interventional procedures are associated with numerous periprocedural adverse events and complications such as pericardial effusion, bleeding or contrast induced nephropathy which correlate with the duration of the procedure.

This study was conducted to investigate whether the duration of the percutaneous LAA occlusion procedure, fluoroscopy time and volume of contrast medium used during the procedure as well as the periprocedural complication rate are associated with the experience of the operators and echocardiographers.

\section{Methods}

\section{Study population}

This retrospective, single-centre study examined LAA percutaneous closures in 43 patients performed in the Cardiology Department of University Hospital No. 1 in Bydgoszcz, Poland between June 2013 and March 2015, listed chronologically. All information required for this study was obtained from the patients' medical records. The indication for LAA closure was a formal contraindication to oral anticoagulation. Table 1 shows the baseline clinical characteristics of the study cohort.

\section{Procedure details}

All device implantations were performed by two operators (AS, SS) using the WATCHMAN device. In all cases the standard pre-procedural assessment included transesophageal echocardiography (TOE) aimed at the detection of intracardiac thrombi (all patients were thrombi-free) and the evaluation of width and depth of the LAA as well as the number and po-
Table 1. Baseline characteristics of the study cohort

\begin{tabular}{ll}
\hline Character & Study cohort $(\mathbf{n}=\mathbf{4 3})$ \\
\hline Age (years) & $70.98 \pm 10.69$ \\
Male gender & $30(69.8 \%)$ \\
Type of AF & \\
Paroxysmal & $16(37.2 \%)$ \\
Persistent & $17(39.5 \%)$ \\
Permanent & $10(23.3 \%)$ \\
CHADS & $2.88 \pm 1.45$ \\
CHA $_{2}$ DS & -VASc \\
HAS-BLED & $4.33 \pm 1.78$
\end{tabular}

$\mathrm{AF}$ - atrial fibrillation

Table 2. Periprocedural adverse events and complications

\begin{tabular}{ll}
\hline Character & Study cohort $(\mathbf{n}=\mathbf{4 3})$ \\
\hline Pericardial effusion* & $16(37.1 \%)$ \\
Bleeding** & $6(14 \%)$ \\
Contrast induced nephropathy & $6(14 \%)$ \\
Pulmonary oedema & $1(2.3 \%)$ \\
Hypertension & $1(2.3 \%)$ \\
Thrombus & $0(0 \%)$ \\
Pulmonary embolism & $0(0 \%)$ \\
Stroke & $0(0 \%)$ \\
\hline
\end{tabular}

*Adverse event - all pericardial effusions were minor and did not require any intervention; **bleeding includes: 1 bleeding from tonsils due to intubation, 1 upper gastrointestinal bleeding and 4 haematomas at the puncture site

sition of different lobes at different plane angulations ranging between $0^{\circ}$ and $135^{\circ}$. At the start of the LAA occlusion programme all procedures were performed under general anaesthesia, while subsequent cases were performed on sedation only. Implantations of the devices were performed via the right femoral vein and transseptal puncture. A careful TOE evaluation was conducted after each device implantation. When the result of the implantation was optimal, the procedure was stopped; otherwise, the device was repositioned or replaced. The outcome of all LAA occlusions was optimal. Table 2 presents periprocedural adverse events and complications.

Contrast-induced nephropathy was defined as acute renal failure in patients with normal kidney function before the intervention using a contrast agent or significant deterioration of renal function in patients previously diagnosed with chronic renal failure. Significant deterioration in renal function was defined, on the basis of laboratory standards, as a decrease in creatinine clearance by $\geq 25 \%$ or an increase in the concentration of creatinine by $\geq 25 \%$ or $\geq 0.5 \mathrm{mg} / \mathrm{dL}(44.2 \mathrm{mmol} / \mathrm{L})$ 


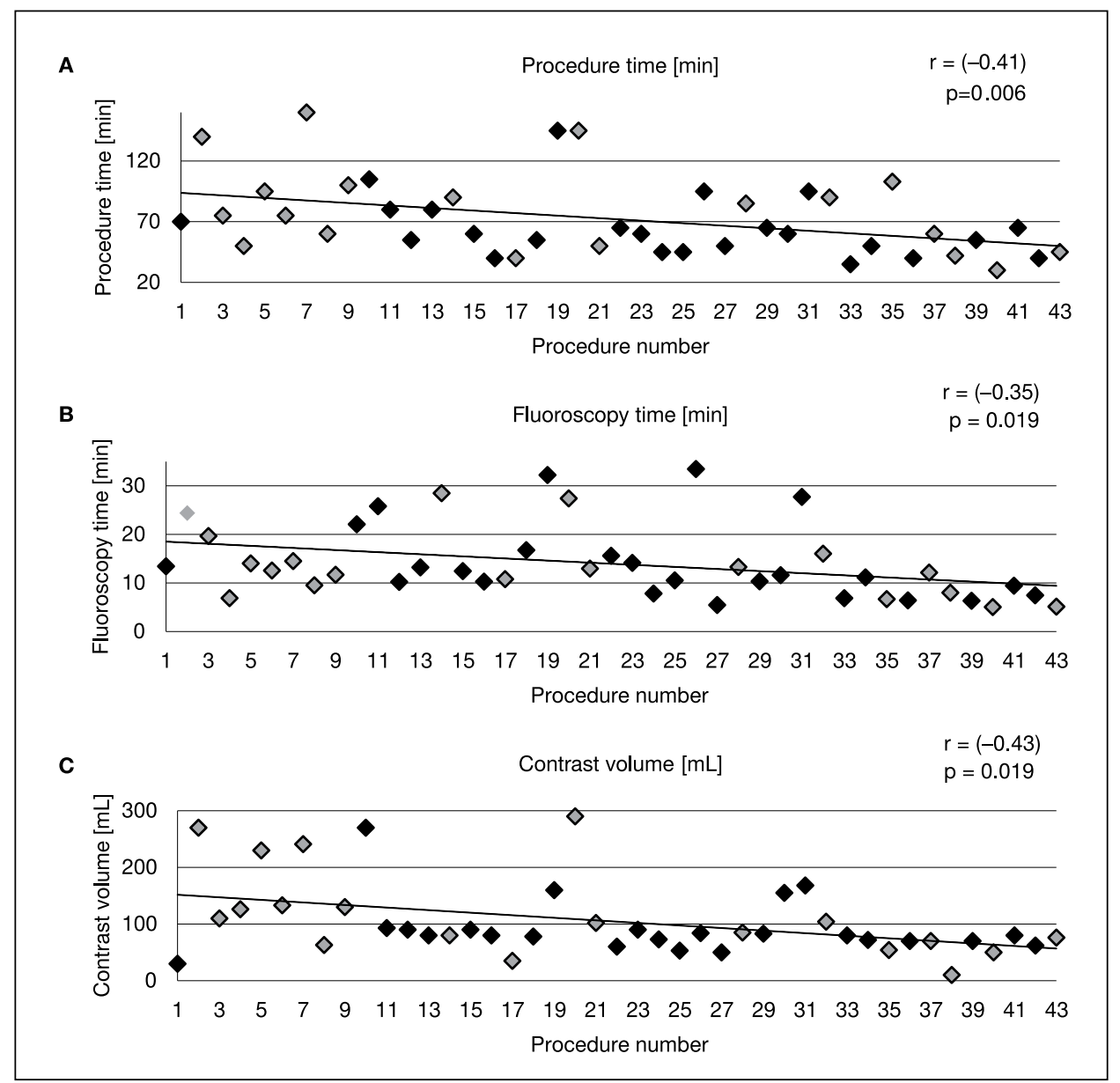

Figure 1A. First approach. Grey marks indicate patients with periprocedural adverse events and complications; B. First approach. Grey marks indicate patients with periprocedural adverse events and complications; C. First approach. Grey marks indicate patients with periprocedural adverse events and complications.

in comparison with the value before the intervention (during 24-72 $\mathrm{h}$ after the administration of contrast agent) [11-14]. Post-procedure pericardial effusion was based on subjective echocardiographic assessment by the same single person (IŚ) in comparison with the baseline echocardiography.

\section{Statistical methods}

We assessed 3 components of the procedural course of LAA closure: procedure time (PT), fluoroscopy time (FT) and contrast volume (CV) used during the procedure. For the purposes of this study it was assumed that the higher the procedure number, the higher operator's experience would be. The patients were listed chronologically. The data were analysed with a dual approach. Firstly, we assessed the learning curve (first approach). Additionally, we divided the patients into 2 groups, comparing the first 22 WATCHMAN device implantation procedures (group A) with the subsequent 21 procedures (group B) and calculated the percentage of reduction in PT, FT and CV (second approach). Continuous variables were reported as mean \pm standard deviation, and categorical variables as numbers and percentages. Continuous variables were compared using the t-test. Correlations between PT, FT, CV and the procedure number were calculated using the Pearson correlation test. P-value $<0.05$ was considered statistically significant. Statistical analysis was performed using Statistica PL software version 8.0.

\section{Results}

\section{First approach}

We found statistically significant reductions in PT $(p=0.006)$, FT $(p=0.019)$ and CV $(p=0.004)$ along with the increasing operators' and echocardiographers' experience (Fig. 1). The correlation between the pro- 
Table 3. Second approach

\begin{tabular}{llll}
\hline Variable & Procedure time [min] & Fluoroscopy time [min] & Contrast volume [mL] \\
\hline Overall average & $71.86 \pm 31.77$ & $13.96 \pm 7.57$ & $104.19 \mathrm{ml} \pm 66.07$ \\
Group A average & $83.41 \pm 36.49$ & $16.59 \pm 7.25$ & $129.14 \mathrm{ml} \pm 79.81$ \\
Group B average & $59.76 \pm 21.70$ & $11.2 \pm 7.21$ & $78.05 \mathrm{ml} \pm 33.82$ \\
Reduction rate (\%) & 28 & 33 & 40 \\
p-value & $\mathrm{p}=0.006$ & $\mathrm{p}=0.019$ & $\mathrm{p}=0.004$ \\
\hline
\end{tabular}

cedure number and $\mathrm{PT}$ as well as $\mathrm{CV}$ was moderate $[r=(-0.41) ; r=(-0.43)$, respectively], while only a weak correlation was found between FT and the procedure number $[r=(-0.35)]$.

\section{Second approach}

The overall average PT was $71.86 \mathrm{~min} \pm 31.77$. The average PT was $83.41 \mathrm{~min} \pm 36.49$ in group $\mathrm{A}$ and 59.76 min \pm 21.70 in group $B$, translating into a $28 \%$ reduction in $\mathrm{PT}$.

The overall average FT was $13.96 \mathrm{~min} \pm 7.57$. The average $F T$ in group $A$ was $16.59 \mathrm{~min} \pm 7.25$ and $11.2 \mathrm{~min} \pm 7.21$ in group $B$, with a reduction in FT by $33 \%$.

The overall average CV was $104.19 \mathrm{ml} \pm 66.07$, with the average volume of $129.14 \mathrm{~mL} \pm 79.81$ in group $A$ and $78.05 \mathrm{~mL} \pm 33.82$ in group $B$, resulting in a reduction of CV by $40 \%$.

The number of patients with periprocedural adverse events and complications in group A was 12 (55\%) and 7 (33\%) in group B (Tab. 3).

\section{Discussion}

The percutaneous LAA closure with the WATCHMAN device has been proved not only to be superior to warfarin therapy [8], but also feasible [15] and relatively safe [8, 16]. However, safety data on percutaneous LAA closure arise from centres with considerable expertise in the procedure or from clinical trials which might not be reproducible in general clinical practice. Badheka et al. [17] demonstrated that the frequency of in-hospital adverse outcomes associated with this procedure is higher in the real-world population than in the clinical trials (Fig. 2).

LAA occlusion is often a difficult procedure due to the three-dimensional variable nature of the LAA anatomy [18]. Numerous studies reported relatively high rates of periprocedural complications in patients who underwent this procedure $[7,8,15]$. Reddy et al. [8] and Maisel [19], on the other hand, implied that the complications associated with this procedure are related to the operator's lack of experience and that they are decreas-

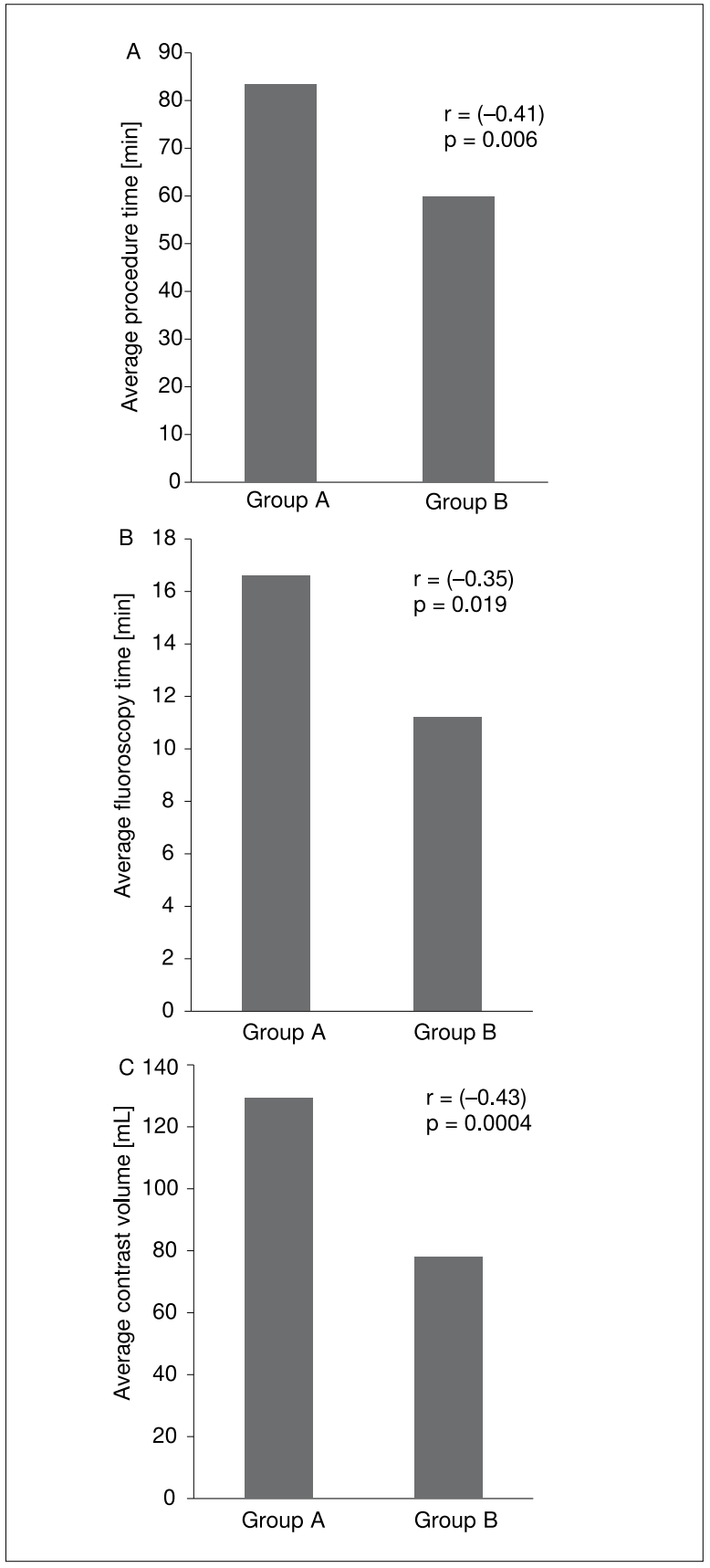

Figure 2. Average procedure time (A) and fluroscopy time (B) and contrast volume (C) 
ing over time following the learning curve. The overall average FT in our study was $13.96 \mathrm{~min} \pm 7.57$. Similar FT (13.7 $\pm 6.7 \mathrm{~min})$ was reported by Gafoor et al. [17] who used the Amplatzer Cardiac Plug (ACP) in a highly experienced German centre. However, it should be highlighted that the FT in our centre significantly decreased to $11.2 \mathrm{~min} \pm 7.21$ in group B (last 21 patients). It has been shown that further PT reduction may be achieved using the "shape-the-sheath" method [18]. This method helps to conform delivery systems to obtain better access to the LAA and ensure stable position. However, further experience with this procedure optimization technique is warranted. Early and late outcome can be also related to the method of LAA occlusion. According to an experimental study performed by Kar et al., [20] LAA closure with the Watchman device does not obstruct or impact the adjacent heart structures and is associated with a favourable local healing response as compared with the Amplatzer Cardiac Plug [20].

Our study suggests that not only adverse events and complications but also the duration of the procedure depends on both operators' and echocardiographers' training level, and potentially on the method of anaesthesia. These two factors might be attributable to each other, however, further studies are required to prove this thesis.

The clinical implication of our study is that as long as there are relatively small target groups of patients qualified for LAA closure, the procedures should be performed only in a limited number of centres providing highly qualified staff in order not to expose patients to the potential risk factors resulting from excessive prolongation of the procedure duration. However, the demand for skilled operators and echocardiographers is likely to grow soon, as LAA closure is a highly promising and effective alternative to oral anticoagulation in patients with atrial fibrillation and might become more widespread in the near future.

\section{Conclusions}

The operator's and echocardiographer's experience in left atrial appendage closure with the WATCHMAN device influences the procedure duration. We noticed a statistically significant reduction of PT, FT and CV. The effect of the learning curve observed in this study has important implications for patient safety.

\section{References}

1. Wyndham CR. Atrial Fibrillation - The Most Common Arrhythmia. Tex Heart Inst J 2000; 27: 257-267.

2. Zoni-Berisso M, Lercari F, Carazza T, Domenicucci S. Epidemiology of atrial fibrillation: European perspective. Clinical Epidemiology 2014; 6: 213-220

3. Wolf PA, Abbot RD, Kannel WB. Atrial fibrillation as an independent risk factor for stroke: the Framingham study. Stroke 1991; 22: 983-988.

4. Odell JA, Blackshear JL, Davies E et al. Thoracoscopic obliteration of the left atrial appendage: potential for stroke reduction. Ann Thoracic Surg 1996; 61: 565-569.

5. Gottlieb LK, Salem-Schatz S. Anticoagulation in atrial fibrillation: does efficacy in clinical trials translate into effectiveness in practice? Arch Intern Med 1994; 154: 1945-1953.

6. Ramlawi B, Abu Saleh WK, Edgerton J. The Left Atrial Appendage: Target for Stroke Reduction in Atrial Fibrillation. Methodist Debakey Cardiovasc J 2015; 11: 100-103

7. Holmes DR, Reddy VY, Turi ZG et al. Percutaneous closure of the left atrial appendage versus warfarin therapy for prevention of stroke in patients with atrial fibrillation: a randomised non-inferiority trial. Lancet 2009; 374: 534-542.

8. Reddy VY, Doshi SK, Sievert $\mathrm{H}$ et al. Percutaneous left atrial appendage closure for stroke prophylaxis in patients with atrial fibrillation: 2.3-Year Follow-up of the PROTECT AF (Watchman Left Atrial Appendage System for Embolic Protection in Patients with Atrial Fibrillation) Trial. Circulation 2013: 127: 720-729.

9. Kaul S, Cingolani E, Shehata M et al. How does left atrial appendage occlusion using the Watchman device compare to dabigatran for reducing thromboembolic events in patients with nonvalvular atrial fibrillation? J Am Coll Cardiol 2010; 55: A4.E39

10. Amorosi SL, Armstrong S, Da Deppo L, Garfield S, Stein K. The budget impact of left atrial appendage closure compared with adjusted-dose warfarin and dabigatran etexilate for stroke prevention in atrial fibrillation. Europace, 2014; 16: 1131-1136.

11. Klinger M, Penar J. Ostra niewydolność nerek po stosowaniu radiologicznych środków cieniujących. In: Matuszkiewicz-Rowińska $\mathrm{J}$ (ed.) Ostra niewydolność nerek. Wydawnictwo Lekarskie PZWL, Warszawa 2006; 214-221.

12. Małyszko J, Myśliwiec M. Nefropatia kontrastowa. In: Pasierski T, Myśliwiec M, Imiela J (eds.). Kardionefrologia. Medical Tribune Polska, Warszawa 2006; 365-370.

13. Nowicki M, Masajtis A, Murlikiewicz K. Nefropatia indukowana kontrastem u chorych poddanych kardiologicznym zabiegom interwencyjnym. Pol Przegl Kardiol 2006; 8: 257-262.

14. Toprak O, Cirit M. Risk factors for contrast-induced nephropathy. Kidney Blood Press Res 2006; 29: 84-93.

15. Sick PB, Schuler G, Hauptmann KE et al. Initial worldwide experience with the WATCHMAN left atrial appendage system for stroke prevention in atrial fibrillation. J. Am. Coll. Cardiol 2007; 49: 1490-1495.

16. Wiebe J, Bertog S, Franke J et al. Safety of percutaneous left atrial appendage closure with the Amplatzer cardiac plug in patients with atrial fibrillation and contraindications to anticoagulation. Catheter Cardiovasc Interv 2014; 83: 796-802.

17. Badheka $A O$, Chothani $A$, Mehta $K$ et al. Utilization and adverse outcomes of percutaneous left atrial appendage closure for stroke prevention in atrial fibrillation in the United States: influence of hospital volume. Circ Arrhythm Electrophysiol 2015; 8: 42-48.

18. Gafoor S, Heuer L, Schulz P et al. "A bend in time": Shaping the sheath facilitates left atrial appendage closure. Catheter Cardiovasc Interv. 2015 May 23. doi: 10.1002/ccd.25996 [Epub ahead of print].

19. Maisel WH. Left atrial appendage occlusion - Closure or just the beginning? New Engl J Med 2009; 360: 2601-2603.

20. Kar S, Hou D, Jones R, Werner D et al. Impact of Watchman and Amplatzer devices on left atrial appendage adjacent structures and healing response in a canine model. JACC Cardiovasc Interv 2014; 7: 801-809. 